\title{
O DIREITO À CIDADE ENCLAUSURADO EM CONJUNTOS HABITACIONAIS: A ANÁLISE DO PROGRAMA MINHA CASA MINHA VIDA NO MUNICÍPIO DE JOÃO PESSOA
}

\section{THE RIGHT TO THE CITY ENCLOSED IN GATED COMMUNITY: A ANALISYS OF PROGRAMA MINHA CASA MINHA VIDA IN JOÃO PESSOA}

\author{
${ }^{1}$ Phillipe Cupertino Salloum e Silva \\ ${ }^{2}$ Emerson Erivan de Araújo Ramos
}

\section{RESUMO}

O Direito apresenta-se para a sociedade, a partir de sua doutrina clássica, como um campo técnico e do conhecimento independente, deslocada da realidade material e, especialmente, não influenciada pela divisão de classe. O presente artigo objetiva trazer o direito para a realidade concreta a partir de reflexões críticas sobre a relação entre o Programa Minha Casa Minha Vida (PMCMV) e a questão urbana. Esta análise exige situar a forma de construção em conjunto das habitações do PMCMV e dos condomínios fechados em João Pessoa como um dos elementos caracterizadores da modernidade. A contradição apresentada é central na análise desenvolvida neste artigo, subsidiada pela contribuição bibliográfica de enfoque crítico e fontes documentais. Para tanto, é utilizado método materialista histórico dialético no intuito de rediscutir o déficit habitacional como um dos elementos, e não como único, a ser enfrentado pela questão urbana.

Palavras-chave: Direito à moradia, Questão urbana, Segregação urbana, Capitalismo

\begin{abstract}
The right presents itself to the society, from its classical doctrine, as a technician field and knowledge independent, offset material reality and especially not influenced by the class division. This article aims to bring the law to the concrete reality from critical reflections on the relationship between the Minha Casa Minha Vida (MCMV) and the urban question. This analysis requires situating the form of construction in group of PMCMV and closed condominiums in João Pessoa as one of the characteristic elements of modernity. The contradiction presented is central on the analysis in this article, subsidized by bibliographical contribution of critical focus and documentary sources. For it will use legal and sociological aspects, by literature, documentary and statistical and through the dialectical and historical materialism. Looking up guarantee the accumulation theoretical and political that can face the housing deficit as one of the elements of the urban question.
\end{abstract}

Keywords: Housing right, Urban question, Urban segregation, Capitalism

\footnotetext{
${ }^{1}$ Mestre em Ciências Jurídicas pela Universidade Federal da Paraíba - UFPB, Paraíba (Brasil) Professor de Direito do Trabalho pela Faculdades Integradas de Patos - FIP, Paraíba (Brasil). E-mail: phillipecupertino@ hotmail.com

${ }^{2}$ Doutorando em Sociologia pela Universidade Federal da Paraíba - UFPB, Paraíba (Brasil)

Pesquisador colaborador afiliado ao Núcleo de Estudos em Gênero e Direito pelo CCJ Universidade Federal da Paraíba - UFPB, Paraíba (Brasil). E-mail: eearamos@gmail.com
} 


\section{INTRODUÇÃO}

A insuficiência de moradia torna-se visivelmente um problema social a partir da consolidação da sociedade moderna e do sistema capitalista. A luta pela moradia confunde-se com a própria possibilidade de sobrevivência nos espaços urbanos que, ao longo da história, se transformou no ambiente no qual vive mais da metade da população. Ocorre que o processo de urbanização que se dá pelo capitalismo dificulta o acesso à moradia digna e à vida urbana na medida em que esses direitos básicos são mercantilizados, transformando-se em fonte direta de extração de mais-valia.

O déficit habitacional e as políticas públicas que visam erradicá-lo vem despertando o interesse da comunidade acadêmica, especialmente, após a Conferência das Nações Unidas Habitat II, tendo em conta a sua relação com o meio ambiente, direitos humanos, desenvolvimento social e as questões demográficas. Este espaço deu origem a Declaração de Istambul, documento assinado no Brasil em 1996, momento que a moradia ainda não se encontrava entre os direitos sociais fundamentais expressos na Constituição.

A inserção da moradia no rol de direitos sociais fundamentais mediante a emenda constitucional $\mathrm{n}^{\mathbf{o}} 26$, ano 2000, consolidou uma importante conquista dos movimentos socais e militantes dos direitos humanos diante do reconhecimento da causa, mas que, por outro lado, não garantiu a sua imediata efetivação. Entretanto, acontece que desde antes o Estado lida com a questão habitacional, seja mediante intervenção direta no mercado imobiliário por meio da construção de habitações populares, especialmente a partir de meados da década de 30, seja com a intervenção diferenciada em obras de infraestrutura nos espaços urbanos.

Para além das implicações formais e normativas sobre o direito à moradia, o presente estudo opta por questionar e relacionar a padronização da habitação, voltada para as camadas mais populares e o surgimento de novos produtos imobiliários, os enclaves fortificados, ao processo de acúmulo e reprodução do capital. Fenômenos que permite questionar o direito à cidade em diferentes dimensões, seja entre aqueles que optam pela segregação espacial, seja entre aqueles não tem escolha.

O presente artigo, resultado das discussões desenvolvida na disciplina "Teoria Crítica da Cidadania" ofertada no âmbito do Programa de Pós-Graduação em Ciências Jurídicas da Universidade Federal da Paraíba em 2013. A discussão consiste na compreensão da habitação de conjunto, da opção pelo modelo condominial e pela localização periférica em face dos conjuntos habitacionais do Programa Minha Casa Minha Vida (PMCMV) no município de 
João Pessoa, assim como outros empreendimentos imobiliários que apresentam alguns pontos de convergência com o pacote habitacional do governo. Leva-se em consideração: os conjuntos habitacionais Irmã Dulce, Jardim das Colinas e Manacá, construídos na região periférica de João Pessoa-PB; os residenciais Spazio di Napoli e Eleonora Coutinho, voltados à famílias beneficiárias do PMCMV de renda média até $\mathrm{R} \$ 5.000,00$ e anúncios publicitários do condomínio Gameleiras e Bosque das Orquídeas, voltado para pessoas de classe média alta. Essa análise não pretende ser exaustiva, tanto no que se refere às variadas formas de execução do PMCMV como os outros aspectos relacionados à habitação de conjunto. Nesse sentido

Para tanto, se recorrerá à vertente jurídico sociológica mediante levantamento bibliográfico, documental e estatístico bem como o referencial teórico e metodológico materialista histórico, por permitir o entendimento da constituição e reprodução do capital a partir da trama das relações sociais. Além disso, busca-se vislumbrar a essência da habitação de conjunto, não como algo deslocado da sociedade, mas como a concretização histórica da articulação entre capital, trabalho e Estado.

\section{A PSEDOCONCRETICIDADE DO ESPAÇO PÚBLICO}

O processo de investigação da habitação de conjunto apresenta a permanente preocupação de compreender o universal da sociedade, tendo em vista que este singular atualiza e concretiza o geral. Numa relação dialética, a habitação de conjunto reproduz a mesma sociedade que a gerou, contudo de modo distinto. A dinamicidade do movimento constitutivo que envolve o universal e o singular não permite margem a que as relações sociais obtenham forma acabada.

Para explicar a vida concreta dos homens e mulheres, uma teoria deve realizá-lo a partir das relações de produção da vida material e das relações de poder determinadas historicamente. Deste modo, não é possível o entendimento da essência da questão habitacional se for tratada apenas sob a ótica do crescimento populacional, do processo de êxito rural ou do preço do solo urbano, sem observar as conexões mais profundas e fundamentais que possibilitam esses fenômenos e relacioná-los à produção concreta da existência humana. Ou seja, é a partir da compreensão da produção da existência humana que se pode explicar esta problemática social.

O materialismo histórico apresenta como pressuposto teórico fundante a perspectiva 
que a sociedade é um resultado da dinamicidade da correlação de força das classes sociais antagônicas. Logo, a compreensão da questão habitacional deve, necessariamente, passar pela totalidade das relações sociais com suas possíveis determinações e condicionantes. Deve-se ir a além do fenômeno, obter o movimento e explicar as relações sociais.

Portanto, para o entendimento da questão habitacional bem como sua relação com o direito à cidade, que não é possível compreender de imediato, mostra-se necessário apanhar o fenômeno e decompô-lo e recompô-lo, realizar a análise de seus elementos e sua síntese, ultrapassar a aparência e compreendê-lo em sua essência. A dialética caminha além do mundo habitacional reificado, como algo isolado e independente. Busca-se superar sua fixidez e naturalidade, situando-o em sua derivação como produto da práxis social, onde o capital, trabalho e Estado vão se constituindo enquanto elementos básicos.

Nesse sentido, é fundamental ter a compreensão que o espaço público atual, supostamente possibilitador de encontros impessoais e anônimos e de co-presença dos diferentes grupos sociais é herdeiro da modernidade e no plano concreto assumem, por outro lado, a desigualdade e a segregação como valores estruturantes. Isto é, representa a psedoconcreticidade que Karel Kosik denominou de "[...] fetichista e aparente objetividade do fenômeno.” (1976, p. 51). Logo, exige-se a análise da realidade dos fatos a partir da totalidade cuja "[...] a inexistência de contradições a tornaria vazia e inerte", ao mesmo tempo em que “as contradições fora da totalidade são formais e arbitrárias.” (KOSIK, 1976, p. 51).

O caráter dialético da práxis imprime uma marca indelével em todas as criações humanas, inclusive sobre a relação entre as habitações em conjunto e a cidade, seja enquanto espaços públicos ou privados. Apresentam um duplo caráter em indissolúvel unidade: é expressão da realidade, e, ao mesmo tempo criador da realidade. Contudo, a condição de sujeito protagonista da construção desta realidade é mascarada para o povo, que nas palavras de Gramsci, representa "o conjunto de classes subalternas de cada tipo de sociedade que existiu até hoje" ([19-] apud PORTELLI, 1977, p. 27).

Pode-se afirmar que a conformação dos espaços públicos é inevitavelmente desigual, tendo em vista que entre as transformações da modernidade está o desenvolvimento do sistema capitalista, que se fundamenta na desigualdade e depende da escassez, inclusive de moradia, para sua manutenção e reprodução. O poder público, motivado por interesses privados, pode representar um papel determinante neste processo ao proporcionar uma infraestrutura diferenciada das demais localidades, possibilitando, portanto, a manutenção da escassez em outros espaços. 
Nesse sentido, Milton Santos (2005) considera que o próprio poder público, representando e se confundindo com as classes dominantes, se torna criador privilegiado da escassez ao passo que estimula a especulação e, simultaneamente, permite a produção de espaços vazios dentro das cidades. A presença destes elementos impende, para o referido autor, o enfrentamento real do "problema da habitação, empurra a maioria da população para as periferias; e empobrece ainda mais os mais pobres, forçados a pagar caro pelos precários transportes coletivos e a comprar caro bens de um consumo indispensável e serviços essenciais que o poder público não é capaz de oferecer." (2005, p. 123).

Cumpre mencionar que a riqueza é produzida, para Harvey (1980), num sistema que também se fundamenta na escassez, para seu funcionamento. Logo se a escassez fosse eliminada, “[...] a economia de mercado, que é a fonte de riqueza produtiva no capitalismo, desapareceria.” (HARVEY, 1980, p. 120). Não obstante, o capitalismo está continuamente aumentando sua condição produtiva. Contudo, para resolver essa questão muitas instituições e mecanismos se formam para garantir que a escassez não desapareça, tendo em vista que a “escassez não pode ser eliminada sem também eliminar-se a economia de mercado.” (HARVEY, 1980, p. 120).

Por sua vez, o individualismo, a neutralidade e a competição, valores presentes no mundo moderno capitalista e fundantes na conformação dos princípios liberais, bem como a desconsideração da existência de luta de classes, reforçam a mediocridade da vida cotidiana, cujas classes subalternas absorvem tais valores e se apropriam do discurso das classes dominantes como algo próprio de seus interesses. É por meio da mediocridade que "[...] o cotidiano se normaliza ao gosto das classes dominantes." (CARVALHO, 2000, p. 23). Permite que os seres humanos ignorem a escassez (moradia, alimentos, recursos energéticos etc) determinante no sistema vigente e ao em vez de se reivindicarem enquanto seres que lutam pela emancipação, opta pelo status de consumidores, nas palavras de Maria do Carmo Brant Carvalho, "[...] um robô capaz de consumismo, dócil e voraz" que abdica de sua "[...] condição de sujeito, cidadão.” (2000, p.24).

As ruas dos centros das cidades, enquanto espaço público, transformaram-se em rede organizada para e pelo consumo. A velocidade da circulação dos seres humanos é então pensada e determinada pela possibilidade de perceber as vitrines, de comprar as mercadorias expostas. Logo, o tempo torna-se o tempo-mercadoria e a rua passa a ser regida sobre essa mesma lógica, o do rendimento e do lucro. É dessa forma que a vida cotidiana torna-se também o espaço da mediocridade, determinando, por meio da massificação, comportamentos 
acríticos e anônimos.

Por outro lado, a conformação dos conjuntos habitacionais populares em formato de condomínios fechados representa uma possível supressão de espaços públicos onde a presença de muros e guaritas, segundo Teresa Caldeira (1997), os transformam em espaços aparentemente privatizados, fechados e monitorados para moradia. Espaços protegidos da crescente violência das cidades, não mais limitadas às grandes metrópoles.

Por fim, é importante ressaltar que o estudo aqui realizado opta por não adjetivar a habitação de conjunto para camadas populares enquanto enclaves fortificados a partir da perspectiva apresentada por Teresa Caldeira (1997) que envolve entre este fenômeno aos shopping centers, centros empresariais, condomínios de luxo etc. Para a autora estes produtos imobiliários “[...] geram cidades fragmentadas em que é difícil manter os princípios básicos de livre circulação e abertura dos espaços públicos que serviram de fundamento para a estruturação das cidades modernas." (CALDEIRA, 1997, p. 155). De um lado há algumas formas de habitação inseridas em condomínios fechados voltados aos grupos sociais de alta renda, e do outro há grupos de renda média ou baixa atraídos por esta forma moderna de viver nas cidades, fora dela e negando os espaços públicos. Essas formas variadas de inserção no espaço ocorrem por diferentes motivações e são inclusive incentivadas pelo próprio poder público.

\section{A NATUREZA EMBALADA EM ENCLAVES FORTIFICADOS}

A cidade representa um produto, no sentido amplo, assumindo a característica de obra, muito além de um simples produto material. Nas cidades se produzem objetos, coisas, mas o fundamental é que nela se produzem as relações sociais, ou seja, a produção e a reprodução de seres humanos por seres humanos, assim como a sua própria consciência. Logo, a cidade como um resultado do trabalho alienado de homens e mulheres produzem consciências alienadas.

A dimensão de espaço recortado, vendido aos pedaços, remete ao desenvolvimento do mundo da mercadoria que alcança o espaço. O espaço social, produto do trabalho social de homens e mulheres, torna-se elemento gerador de mais-valia. Portanto, "o espaço inteiro entra na produção como produto através da compra, da venda, da troca de parcelas do espaço" (LEFEBVRE, 1999, p. 142), em que alguns têm o privilégio de viver nas áreas urbanizadas, que recebem os principais investimentos públicos e privado, enquanto os sujeitos 
historicamente subalternizados na sociedade permanecem segregados.

É inegável que a produção do espaço em suas mais variadas formas é fonte de lucro para uns e desespero para uma grande maioria assalariada que compromete parte do orçamento para custear a moradia e ao mesmo tempo circular pela cidade. A apropriação pelo modo de produção capitalista do processo de urbanização e consequentemente do mercado imobiliário "vem tornando cada mais dispendiosa para os brasileiros a sobrevivência nas cidades devido ao crescimento nos preços de aluguéis e no metro quadrado dos imóveis" (SILVA, ALCÂNTARA, 2014, p.17). O aumento em 30\%, entre 2007 e 2012, do ônus excedente de aluguel ${ }^{1}$, “que passou de 1,75 milhões de domicílios para 2,293 milhões" (IPEA, 2013) e a "variação do preço do metro quadrado dos imóveis anunciados para venda em 16 cidades brasileiras, registrando um aumento no preço médio do metro quadrado de $13,7 \%$ em 2013” (YAZBEK, 2013), contribuem para a restrição do direito à cidade.

Ocorre que o espaço público, isto é, determinadas ruas e bairros com uma boa infraestrutura são tornados raro para que alcance um valor mais elevado no circuito da compra e venda. O Estado, motivado e confundido com os interesses privados, pode representar um papel determinante neste processo ao proporcionar uma infraestrutura diferenciada das demais localidades, possibilitando, portanto, a manutenção da escassez em outros espaços.

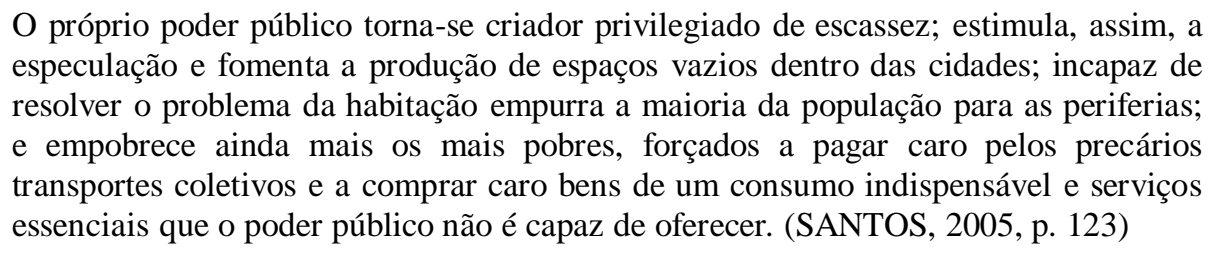

Por sua vez, a raridade produzida no espaço é de natureza contraditória, já que o raro não significa único ou incomum, pelo contrário, a raridade localmente manifestada nos espaços urbanos compreende a repetição de padrões arquitetônicos, urbanísticos e paisagísticos, possíveis de se encontrar em qualquer espaço urbano mundial que passe por dinâmicas parecidas. O espaço se insere, contribui e ao mesmo tempo reflete a desigualdade social determinante para o capitalismo.

Os condomínios fechados, assim como os shopping centers, representam produtos que expõem e reúnem novas formas e práticas para antigas ações (consumo, lazer e moradia) conformando na sua materialização para o processo de acumulação de capital. Em termos gerais, esses produtos imobiliários formam parte de uma categoria mais ampla, aqui

\footnotetext{
${ }^{1}$ O ônus excessivo corresponde ao número de famílias urbanas com renda de até três salários mínimos que moram em casa ou no apartamento (domicílios urbanos duráveis) e que despendem $30 \%$ ou mais de sua renda com aluguel.
} 
denominado por enclaves fortificados, isto é, espaços privatizados, fechados e monitorados para moradia, consumo, lazer e trabalho.

\begin{abstract}
Enclaves fortificados são espaços privatizados, fechados e monitorados para residência, consumo, lazer ou trabalho. Esses espaços encontram no medo da violência uma de suas principais justificativas e vêm atraindo cada vez mais aqueles que preferem abandonar a tradicional esfera pública das ruas para os pobres, os "marginais" e os sem-teto. Enclaves fortificados geram cidades fragmentadas em que é difícil manter os princípios básicos de livre circulação e abertura dos espaços públicos que serviram de fundamento para a estruturação das cidades modernas. (CALDEIRA, 1997, p. 155, grifo do autor)
\end{abstract}

Os enclaves fortificados respondem aos anseios de um segmento da população, a partir da década de 80, principalmente de maior poder aquisitivo, de se diferenciar, dispondo de seus espaços próprios que não precise ou evite interagir com os espaços urbanos existentes, onde estão presentes, ainda que em desarmonia, todas as classes sociais. Além disso, Corrêa relaciona o surgimento desses produtos "como sinônimo de progresso e bem-estar", tornandose, graças à massiva publicidade, "o mais importante e genérico objeto de consumo" (2010, p. 150). Embora sejam menos freqüentes em cidades pequenas esses empreendimentos podem ser encontrados nas diversas cidades brasileiras. Significam uma nova forma de autosegregação socioespacial que contribuem para a produção de territórios exclusivos e apartados da cidade.

O espaço da periferia urbana ou um de seus setores constitui-se em local privilegiado para os condomínios fechados de luxo, tendo em vista a necessidade de amplos espaços disponíveis, mais facilmente encontradas, na periferia urbana e não nas áreas mais antigas, que se caracterizam, em geral, por uma muito fragmentada propriedade da terra.

As inúmeras 'cidadelas' ou condomínios de luxo, cercados e protegidos por uma
cada vez mais e eficiente sistema de vigilância, são locais onde vive uma classe
média, constituída por descendentes das antigas famílias de ato status que residiam
nos bairros nobres tradicionais, ou por uma classe média emergente, procedente de
bairros de menor status social. (CORRÊA, 2010, p. 157, grifo do autor)

Observa-se que as referidas cidadelas têm poucas ou nulas relações com as suas adjacências, há uma vida comum interna, onde a relação com o mundo extra muro é restrita a certos locais, preestabelecidos e extremamente rotineiros. Encontram-se, geralmente, em espaços afastados da malha urbana onde são mal servidos de transporte público. Portanto, a circulação de ônibus nestes espaços é limitada aos empregados que trabalham localmente e residem em outros locais.

Os enclaves fortificados representam uma auto-segregação espacial com o objetivo de se hierarquizar em relação aos demais lugares da cidade, uma vez que a reprodução do capital separa e tende a ressaltar as especificidades dos lugares para facilitar a sua comercialização. 
Trata-se, nas palavras de Corrêa, "de algo antigo metamorfoseado em novo" (2010, p. 157).

Nesse sentido, os enclaves fortificados tendem a se conformar, especialmente no plano simbólico, a partir de sua valorização diferenciada, como a forma moderna de morar, própria dos grupos de maior poder aquisitivo ou daqueles que se esforçam para fazer parte desse segmento. Ainda mais, em cidades menos desenvolvidas, onde os menores preços da terra urbana (influenciados pela maior disponibilidade de áreas loteáveis) e os custos de vida e de construção comparativamente menores facilitam o acesso a esse tipo de produto imobiliário até para grupos de poder aquisitivo médios.

É possível observar, inclusive, que o direito à natureza (ao campo e à suposta natureza pura) adentrou para a prática social há algum tempo em favor de lazeres associados as moradias privilegiadas, como é possível de ser observado em alguns enclaves fortificados. Nos dizeres de Lefebrve, "a natureza entra para o valor de troca e para a mercadoria; é comprada e vendida" (1969, p.107).

Ocorre que os lazeres comercializados, industrializados, conformados institucionalmente, no contexto do sistema capitalista, destroem essa "naturalidade". Logo, os referidos produtos imobiliários se apropriam da escassez de "naturalidade", por se tornarem uma especificidade, e a oferecem nestes empreendimentos, onde seus possuidores ou proprietários possam usufruir e trafegar por ela mesmo morando nas cidades.

O condomínio Bosque das Orquídeas, localizado no bairro de luxo Altiplano Cabo Branco, do município de João Pessoa, representa um exemplo clássico de enclaves fortificados que se apropria do marketing verde para oferecerem a natureza como mais um valor de troca. Isto é, uma mercadoria a ser consumida por aqueles puderem pagar pelo privilégio de morar num condomínio fechado em contato com a suposta naturalidade, conforme exposto na citação abaixo.

\section{O Orquídeas tem como destaque um bosque repleto de verde, com árvores nativas, uma "casa de Tarzan" e trilhas para caminhadas. É um lugar abençoado pela natureza e uma escolha perfeita para quem valoriza uma vida saudável em contato com o meio ambiente) $)^{2}$.}

Em tempos de combate ao aquecimento global e ao efeito estufa, a valorização e o uso de elementos do meio ambiente natural, inclusive no próprio prefixo do referido empreendimento citado acima, são táticas mercadológicas cada vez mais comuns em anúncios publicitários. O mesmo ocorre em relação ao condomínio Gameleiras, localizado no mesmo

\footnotetext{
${ }^{2}$ Informações extraídas do endereço eletrônico do empreendimento Ecomax, referente ao condomínio Bosque das Orquídeas, 2013.
} 
bairro supracitado de João Pessoa, que se autoproclama em compromisso com "o meio ambiente e com a sustentabilidade" ${ }^{3}$.

Nesse contexto, os habitantes dos espaços urbanos transportam o urbano consigo, ainda que não carreguem a urbanidade. Tais espaços supracitados, antes parte da zona rural ou áreas pouco habitadas, onde ainda é possível ser encontrado elementos do meio ambiente natural, por esses empreendimentos passam a ser colonizados, onde o contato com campo perde as qualidades e encantos da vida camponesa. A reivindicação da natureza e o desejo de aproveitar dela representam um evidente desvio do direito à cidade. Conforme defende Lefebrve, "esta última reivindicação se anuncia indiretamente, como tendência de fugir à cidade deteriorada e não renovada, a vida urbana alienada antes de existir realmente" (1969, p. 107). Portanto, a influência do estilo de vida mais próximo da natureza, e afastado do universo concentracionista das cidades (enquanto a cidade apodrece ou explode), pode ser visto como uma ótima oportunidade para a propagação dos condomínios fechados nas regiões periféricas enquanto produto imobiliário diferenciado.

\section{O PRIVILÉGIO DA CASA PRÓPRIA}

A suposta efetivação do direito à moradia para todos e todas, por meio do Programa Minha Casa Minha Vida, envolve paralelamente dois fatores que se complementam: a especulação imobiliária promovida nos circuitos rentistas e financeiros que operam sobre a expectativa de valorização imobiliária e a consolidação do padrão periférico de urbanização, por meio da construção de grandes conjuntos habitacionais, em regra, localizado nas zonas periféricas. Contudo, o estudo aqui realizado opta por analisar o direito à cidade e moradia a partir do processo de padronização e periferização da moradia popular inserida em espaços urbanos.

A questão da padronização arquitetônica de habitações populares é um reflexo do desenvolvimento histórico da arquitetura, área esta que não escapou à racionalização da sociedade industrial. Umbilicalmente ligada aos movimentos artísticos vanguardistas como o Construtivismo russo e o Neo-Plasticismo holandês, a arquitetura moderna era a expressão máxima de uma estética da máquina. Para Subirats (1991), a integração das vanguardas históricas com a produção industrial e a economia capitalista sempre foi intencionada, porém o ideal utópico renovador do período entre guerras se perdeu.

\footnotetext{
${ }^{3}$ Id., 2013.
} 
A utopia moderna artística de transformação da realidade se manifestava, em uma das suas formas, na arquitetura moderna através da criação de conjuntos habitacionais voltados para a classe trabalhadora. A habitação, vista como um sistema, era projetada em conjunto, do simples utensílio como um garfo à própria construção, dentro de uma lógica científica de produção. Despojados de ornamentos, seguindo uma estética cartesiana, esses projetos seriam mais fáceis e mais baratos de se produzir, mais adequados à produção industrial.

Embora não se possa classificar estilisticamente as habitações do programa MCMV no estilo da arquitetura moderna, fazem em seu ideal a lógica da produção industrial em massa de construções padronizadas para a classe trabalhadora. Porém, da mesma maneira que o caráter revolucionário das criações vanguardistas se perde e os valores do funcionalismo, do universalismo e do não-burguês, como elenca Wolfe (1990), se tornam vazios e cristalizam-se como regras formais, a padronização dos conjuntos habitacionais do MCMV corresponde à reprodução de um princípio de ordem esmagador inserido no mercado imobiliário.

A partir da análise das unidades habitacionais entregues até o final do ano de 2012, o processo instalação das unidades habitacionais do MCMV no município de João Pessoa, especialmente entre as famílias que possuem uma renda média até três salários mínimos (classificada por faixa 1), vem também optando, pelo padrão periférico de urbanização que contribui, inevitavelmente, para segregação espacial.

A título de exemplificação, pode-se afirmar que, entre as unidades habitacionais do MCMV direcionados para as camadas mais populares em João Pessoa, a sua maioria estão localizados em bairros periféricos, por exemplo, como bairro das Indústrias, Gamares, Colinas do Sul, Jardim Veneza e Paratibe. Afastados do centro da cidade, segundo defende Lefebrve, “[...] o proletariado acabará de perder o sentido da obra. Afastado dos locais de produção, disponível para empresas esparsas a partir de um setor de habitat, o proletariado deixará se esfumar em sua consciência a capacidade criadora. A consciência urbana vai se dissipar." (1969, p. 22).

O padrão periférico de urbanização soma-se ao formato dos loteamentos fechados que funciona em sistema de condomínio, como ocorre nos residencial Manacá (Figura 3 - Anexo A), Irmã Dulce (Figura 1 - Anexo A), Anayde Beiriz (Figura 2 - Anexo A) ${ }^{4}$. Por sua vez, o isolamento físico que caracteriza estes conjuntos habitacionais, embora deem ênfase ao valor do que é restrito e privado, desvalorizando o que é público e aberto na cidade, não permite os

\footnotetext{
${ }^{4}$ Os residenciais Anayde Beiriz, Manacá e Irmã Dulce, os primeiros empreendimentos do PMCMV no estado da Paraíba, movimentaram a economia local e custaram aos cofres públicos, respectivamente, R\$ 19.661.109,39, $\mathrm{R} \$$ 9.028.000,00 e 53.839.999,08.
} 
envolverem na categoria dos enclaves fortificados conforme exposto no tópico anterior.

As unidades habitacionais do MCMV são, em regra, apresentadas de forma padronizada, isto é, possuem a mesma fachada e configuração interna semelhante, isto é, por volta de 40 a 60 metros quadrados para cada família. Até 2012 em João Pessoa, a quantidade de unidades habitacionais, localizado no mesmo loteamento, variam entre 244 (Residencial Manacá) à 1240 (Residencial Irmã Dulce) apartamentos.

A conformação massificada de habitações em zonas periféricas e em grandes loteamentos é justificada por seu baixo custo e celeridade na conclusão. Por outro lado, conforma, visualmente, a criação de verdadeiros blocos de cidades, como é o caso do Residencial Irmã Dulce, composto por três empreendimentos, Irmã Dulce A que contempla 440 apartamentos, distribuídas em 110 blocos, Irmã Dulce B com 480 apartamentos em 120 blocos e o Irmã Dulce C com 320 famílias em 120 blocos. Frisa-se que as unidades deste residencial possuem apenas $42,03 \mathrm{~m}^{2}$ de área privativa.

Conforme ilustrações em anexo, a concentração destas unidades habitacionais num mesmo espaço pode passar a impressão de um mar uniforme de moradias onde não há entre elas elementos de uma vida urbana, inclusive aqueles mais banais, como pequenos mercados, mercearias, padarias etc. São blocos de cidades para as classes populares, criadas e entregues unilateralmente pelas construtoras para serem meros dormitórios que subjugam a criatividade e o improviso dos homens e mulheres em intervirem na realidade que os rodeiam.

O Residencial Irmã Dulce, descrito acima, além de estar situado numa zona de adensamento entre o urbano e o rural, envolve uma quantidade de unidades habitacionais que supera aproximadamente $23 \%^{5}$ dos municípios do estado da Paraíba, em relação a presença de domicílios permanentes nestas localidades (CENSO DEMOGRÁFICO, 2010). Em outras palavras, somente o Residencial Irmã Dulce é superior a 51 municípios do estado, ainda que não leve em consideração a quantidade de habitantes permanentes. Representa uma constatação fática que justifica o termo "bloco de cidades" usado anteriormente por exibirem uma quantidade exorbitante de moradias localizada num mesmo espaço em conjunto.

Ainda assim, o pacote habitacional aqui observado pode ser bem recepcionado, especialmente pelas classes mais populares, e inclusive os setores médios, isto é, parte da classe média, que podem ter acesso as unidades habitacionais voltados para famílias com uma renda entre três salários mínimos. Materializa-se o sonho da casa própria, o fim do aluguel.

5 A referida porcentagem foi obtida mediante a observação da quantidade de domicílios permanentes em cada município paraibano com informações obtidas a partir de dados fornecidos pelo Instituto Brasileiro de Pesquisa, Geografia e Estatística (IBGE) referente as características dos municípios e das suas respectivas populações. 
Por outro lado, a acessibilidade e boa localização das unidades habitacionais envolvidos ao MCMV melhoram progressivamente na medida em que a renda familiar dos beneficiários aumentam.

Em João Pessoa, há também empreendimentos do MCMV direcionados para pessoas com renda familiar entre $\mathrm{R} \$ 1.600,00$ e $\mathrm{R} \$ 3.275,00$ (faixa 2) e até $\mathrm{R} \$ 5.000,00$ (faixa 3).

A existência de empreendimentos distintos relacionados ao Programa Minha Casa Minha Vida mostra que o privilégio de ter a casa própria, que não se confunde mas está relacionado ao direito à moradia, já devem bastar para as classes mais baixas, enquanto aqueles e aquelas que são melhores remunerados podem, isto é, merecem ter o privilégio de viver em melhores bairros e condições. A moradia que se manifesta abstratamente nos tratados internacionais de direitos humanos como um direito de todos, e no plano concreto de forma desigual variando de acordo com a renda familiar. Logo, a desigualdade está permitida, autorizada, isto é, institucionalizada pelo próprio Estado em sintonia com as leis de mercado.

Não seria uma surpresa, portanto, que o Residencial Eleonora Coutinho (Figura 4 Anexo B) ou o Residencial Spazio di Napoli (Figura 5 - Anexo B), ambos situados no município de João Pessoa e que envolvem famílias inseridas na faixa 3, estarem situados respectivamente próximo ao shopping Manaíra (bairro de mesmo nome) e a principal avenida da cidade, a Epitácio Pessoa (bairro Tambauzinho), ambos considerados um das regiões mais prestigiada e valorizada do município em tela.

A composição de iguais edifícios ou unidades habitacionais padronizadas num mesmo espaço é praticamente uma condicionante para a realização de moradia popular, isto é, a garantia de políticas habitacionais para a classe trabalhadora urbana, especialmente da faixa 1. A criatividade, a inovação, o pensamento urbanístico com valores democráticos e populares, propostos pelo pensamento lefebrviano (1968), isto é, que pense a cidade para todos e todas, não orientam a principal política pública habitacional vigente no Brasil que, para garantir sua execução, se rendem aos interesses das construtoras civis privadas.

Os financiamentos do MCMV estimulam e fortalecem o mercado formal de produção de moradia que é o mais importante filão da indústria da produção do urbano e um dos motores do desenvolvimento capitalista no Brasil. Ocorre que este estímulo ao mercado formal não implica necessariamente "uma redução do mercado informal, tampouco um arrefecimento dos antigos mecanismos de espoliação urbana.” (BASTOS, 2012, p. 78).

A perspectiva produtivista predominante no contexto do MCMV que atua simplesmente na construção de "mais casas" rompe com qualquer possibilidade das pessoas, 
para quem serão disponibilizadas tais unidades habitacionais, participarem do processo construção de suas próprias moradias e de também serem sujeitos construtores dos espaço público, isto é, da realidade que os e as rodeiam.

O Estado e a empresa, apesar de possuírem diferentes naturezas, convergem para a segregação. Nas palavras de Lefebrve, “[...] o Estado age sobretudo por cima e a Empresa por baixo (assegurando a habitação e a função de habitar nas cidades operárias e os conjuntos que dependem de uma sociedade, assegurando também os lazeres, e mesmo a cultura e promoção sociais).” (LEFEBRVE, 1968, p. 90, grifo do autor). Estes procuram se apoderar das funções urbanas, assumi-las e assegurá-las ao destruir a forma do urbano, isto é, mediante o Programa Minha Casa Minha Vida, em geral, representado por habitações em forma de conjuntos habitacionais que resultam na absorção do espaço público recortado da cidade mediante muros e grades.

Por outro lado, a conformação da moradia em conjunto, isto é, em formato de condomínio fechado, conforme defende Sobarzo, “[...] também modifica as práticas de consumo comandadas por valores subjetivos e ideológicos que expressam o desejo de dispor desses novos espaços, que passam a ser conceituados como indicadores da modernização.” (2006, p. 101). O novo está sempre nos bens de consumo de um determinado público e naqueles que conferem distinção social. Entre as camadas populares, o fato de possuir a casa própria já lhe confere distinção social, em meio a tantos brasileiros e brasileiras morando de aluguel ou em aglomerados humanos subnormais (assentamentos irregulares, invasões, grotas, baixada, ressacas, mocambos, palafitas, entre outros).

Essa noção de privilégio ou distinção social se manifesta de forma intensa na realidade brasileira onde 11,4 milhões de pessoas $(6,0 \%)$ vivem em aglomerados humanos subnormais e especialmente para microrregião de João Pessoa que são 101.888 pessoas (8,5\%), acima da média nacional (CENSO DEMOGRÁFICO, 2010). Enquanto a escassez for predominante e inevitável, elemento fundante para o sistema capitalista, as condições mínimas de moradias promovidas pelo PMCMV, padronizadas, em zonas de periferias ou não, para muitas pessoas ainda representarão uma conquista de direitos, sem, todavia, promover a democratização dos espaços urbanos e do direito à cidade.

A implantação de uma política habitacional integrada à questão urbana não pode desconsiderar que as cidades brasileiras vivem um cenário que não pode ser mais definido e compreendido em vista da dicotomia "cidade legal' e "cidade ilegal", ou em face da mensuração meramente quantitativa das soluções ao déficit habitacional. Embora o Estatuto 
da Cidade apresente formas de limitar o exercício do poder econômico na produção das cidades, cabe reconhecer que a mera existência de legislação urbana, decretos e normas que regulam o uso e ocupação da terra urbana ainda não são suficientes para promover significativas alterações na conjuntura de segregação socioespacial na qual se encontram as cidades brasileiras $^{6}$.

\section{CONSIDERAÇÕES FINAIS}

A cidade vendida aos pedaços converte-se em parte integrante da reprodução capitalista, não só porque nela são confeccionados e trocados bens materiais e imateriais, ou porque dentro dela, num sentido amplo, a sociedade como um todo é reproduzida. Mas também, num sentido que poderíamos considerar restrito, porque a cidade vem a ser um produto consumido, comprado e vendido, assumindo uma função fundamental na circulação e acumulação de capital. A cidade trata-se de um produto e, ao mesmo tempo, um grande negócio, especialmente para os setores privados que embolsam, com sua produção e exploração, lucros, juros e renda.

A crise urbana e questão habitacional, não restrita ao déficit habitacional, são, antes de qualquer coisa, uma questão de classe social, em decorrência da hegemonia do modo de produção capitalista no processo de urbanização e consequentemente na elaboração das políticas públicas e das normas jurídicas. Portanto, o que se entende por crise urbana na verdade se trata de uma crise do capitalismo que é permanente, tendo em vista que as cidades são hoje o principal local onde se dá a reprodução da força de trabalho. Nesse sentido, a crise urbana manifesta-se diante de uma disputa básica, como pano de fundo, entre aqueles que querem dela condições de dignas de sobrevivência e aqueles que visam apenas extrair vantagens pecuniárias.

A forma que o Programa Minha Casa Minha Vida se conforma no município de João Pessoa descarta a possibilidade de tratar o déficit habitacional bem como a questão urbana por meio de políticas que envolva toda cidade, isto é, aproveitando os espaços já existente e promovendo uma melhoria na vida urbana, por meio de projetos que ampliem a mobilidade urbana, espaços culturais, infraestrutura e serviços públicos em todos bairros.

\footnotetext{
${ }^{6}$ A concretização das políticas urbanas e habitacionais está diretamente envolvida ao modo de como está estabelecida a composição político-institucional brasileira, seja da presidência da república, seja dos ministérios, das secretarias e dos órgãos envolvidos nessas temáticas, levando em consideração ainda as composições e competências de cada ente federativo, especialmente, o municipal.
} 
A lógica produtivista que promove a construção em blocos de habitações populares em zonas periféricas é uma manifestação clara que o fator econômico, ou seja, os interesses da iniciativa privada da construção civil, ainda são postos acima do pensamento urbanístico. Põemse um limite ao direito à cidade em nome da possibilidade de transformar a moradia popular em mais uma mercadoria lucrativa.

O estudo aqui desenvolvido não pretende ser exaustivo e desde já objetiva apontar outros elementos que podem ser investigado no que se diz respeito a relação entre o Programa Minha Casa Minha Vida e o direito à cidade como a influência da especulação imobiliária na conformação das políticas públicas habitacionais e a discussão a cerca dos demais direitos envolvidos na efetivação do direito à moradia nesta circunstância (cultura, mobilidade urbana, meio ambiente, saúde, educação etc).

A existência de privilégios no acesso aos novos produtos imobiliários e a escassez de moradia são elementos próprios do sistema capitalista, contudo não podem ser vislumbrados como realidades intactas. A luta pela moradia deve se apegar a um pensamento urbanístico que descarte as políticas públicas que negam o direito à cidade ao povo e que perceba a democratização e o acesso crescente aos espaços públicos como um importante elemento potencializador da elevação da consciência humana e da superação do trabalho alienado.

\section{REFERÊNCIAS BIBLIOGRÁFICAS}

ARANTES, Pedro Fiori; FIX, Mariana. Como o governo Lula pretende resolver o problema da habitação. Passa Palavra, São Paulo, 6 ago. 2009. Disponível em: <http://passapalavra.info/?p=9445>. Acesso em: 04 de mai. 2012.

BASTOS, Rodrigo Dantas. Economia política do imobiliário: O Programa Minha Casa Minha Vida e o preço da terra urbana no Brasil. 2012. 106 f. Dissertação (Mestrado em Sociologia)-Instituto de Ciências Humanas e Filosofia, Campinas, 2012.

BRASIL. Lei n. 11.977, de 7 de julho de 2009. Diário Oficial [da] República Federativa do Brasil, Poder Executivo, Brasília, DF, 7 jul. 2009. Disponível em: <http://www.planalto.gov.br/ccivil_03/_ato2007-2010/2009/lei/111977.htm>. Acesso em: 19 jul. 2013.

CALDEIRA, Teresa Pires do Rio. Enclaves fortificados: a nova segregação urbana. Novos Estudos, n. 47, p. 155-176, mar. 1997. Disponível em: <http://reverbe.net/cidades/wpcontent/uploads/2011/08/Enclaves-fortificados_segregacao-urbana.pdf > . Acesso em: 28 jul. 2013. 
CAIXA Econômica Federal. Programa Minha Casa Minha Vida - faixa 1 construtoras e empreendimentos. Disponível em:

<http://downloads.caixa.gov.br/_arquivos/caixa/acessoinformacao/pmcmv_faixa1_empreendi mentos_construtoras.pdf>. Acesso em: 28 jul. 2013.

CENSO 2010: 11,4 milhões de brasileiros (6,0\%) vivem em aglomerados subnormais. IBGE - Instituto Brasileiro de Geografia e Pesquisa, Brasília, 21 dez. 2011. Disponível em:

<http://saladeimprensa.ibge.gov.br/noticias?view=noticia\&id=1\&busca=1\&idnoticia=2057>. Acesso em: 28 jul. 2013.

CENSO demográfico 2010. IBGE - Instituto Brasileiro de Geografia e Estatística,

Cidades@, Brasília, DF, 2013. Disponível em: <http://www.ibge.gov.br/cidadesat/index.php>. Acesso em: 29 jul. 2013.

CORRÊA, Roberto Lobato. Inovações espaciais urbanas - algumas reflexões. Revista

Cidades, São Paulo, v. 7, n. 11, p. 151-159, 2010.

ENGELS, Friedrich. A questão da habitação. São Paulo: Acadêmica, 1988.

HARVEY, David. A justice social e a cidade. Tradução Armando Corrêa da Silva. São Paulo: Hucitec, 1980.

LEFEBVRE, Henri. Direito à cidade. Tradução T. C. Netto. São Paulo: Editora Documentos, 1968.

LOCKE, Jonh. Segundo Tratado do Governo Civil. Tradução Magda Lopes e Marisa Lobo da Costa. Petrópolis: Vozes, 2008.

LUCIANO Agra entrega 244 casas do Residencial Manacá nesta quarta. Prefeitura de João Pessoa, João Pessoa, PB, 06 mar. 2011. Disponível em:

$<$ http://www.joaopessoa.pb.gov.br/luciano-agra-entrega-244-casas-do-residencial-manacanesta-quarta/>. Acesso em: 29 jul. 2013.

KOSIK, Korel. Dialética do concreto. Tradução: Célia Neves; Alderico Toríbio. 3. ed. Rio de Janeiro: Paz e Terra, 1976.

MARX, Karl. Sobre a questão judaica. Tradução Nélio Schneider. São Paulo: Boitempo, 2010.

MINISTÉRIO DAS CIDADES. O ministério. Brasília, DF, 2013. Disponível em: <http://www.cidades.gov.br/index.php/o-ministerio>. Acesso em: 18 ago. 2013.

PORTELLI, Hugues. Gramsci e o bloco histórico. Tradução Angelina Peravalva. São Paulo: Paz e Terra, 1977.

PMJP entrega novas moradias a cerca de cinco mil pessoas nesta quinta. Prefeitura de João Pessoa, João Pessoa, PB, 05 set. 2012. Disponível em:

$<$ http://www.joaopessoa.pb.gov.br/pmjp-entrega-novas-moradias-a-cerca-de-cinco-milpessoas-nesta-quinta/>. Acesso em: 29 jul. 2013. 
PREFEITURA entrega Residencial Anayde Beiriz e beneficia 584 famílias carentes.

Prefeitura de João Pessoa, João Pessoa, PB, 29 mar. 2012. Disponível em:

<http://www.joaopessoa.pb.gov.br/prefeito-entrega-residencial-anayde-beiriz-e-beneficia-584familias-carentes/ >. Acesso em: 29 jul. 2013.

NETTO, José Paulo; CARVALHO, Maria do Carmo Brant. Cotidiano: conhecimento e crítica. 5.ed. São Paulo: Cortez, 2000.

PERUZZO, Dilvo. Habitação: controle e espoliação. São Paulo: Cortez Editora, 1984.

SANTOS, Milton. Pobreza urbana. 2.ed. São Paulo: Editora Hucitec, 1979.

A Urbanização Brasileira. São Paulo: Edusp, 2005.

SHIMBO, Lucia Zanin. Habitação social, habitação de mercado: a confluência entre estado, empresas construtoras e capital financeiro. 2012. $361 \mathrm{f}$. Tese (Doutorado em Arquitetura e Urbanismo)-Escola de Engenharia de São Carlos, São Paulo, 2013.

SILVA, Phillipe Cupertino Salloum e; ALCÂNTARA, Rafaela Cavalcanti de. Da apropriação do urbano pelo Capital à captação da mais-valia urbana: respostas e possibilidades institucionais no ordenamento jurídico-urbanístico brasileiro. In: ROLIM, Renata Ribeiro et. al. Sociologia, Antropologia e Cultura Jurídicas I. João Pessoa: Conpedi, 2014. Disponível em: <http://www.publicadireito.com.br/publicacao/ufpb/livro.php?gt=269>. Acesso em: 10 fev. 2015.

SINOPSE do Censo Demográfico 2010. IBGE- Instituto Brasileiro de Geografia e Estatística, Brasília, DF, 2013. Disponível em: <http://www.censo2010.ibge.gov.br/sinopse/index.php?dados=8 >. Acesso em: 19 ago. 2013.

SOBARSO, Oscar. A produção do espaço público: da dominação à apropriação. Geousp Espaço e Tempo, São Paulo, n. 19, p. 93-111, 2006. Disponível em:

<http://www.geografia.fflch.usp.br/publicacoes/Geousp/Geousp19/Artigo_Sobarzo.pdf>. Acesso em: 29 jul. 2013.

SUBIRATS, Eduardo. Da vanguarda ao pós moderno. 4.ed. São Paulo: Nobel, 1991.

YAZBEK, Priscila. Preços de imóveis sobem 13,7\% e superam a inflação em 2013. Exame, São Paulo, 6 jan. 2014. Disponível em: < http://exame.abril.com.br/seudinheiro/noticias/precos-de-imoveis-sobem-13-7-e-superam-ainflacao-em-2013>. Acesso em: 27 jul. 2014.

WOLFE, Tom. Da Bauhaus ao nosso caos. Tradução de Lya Wyler. 4.ed. Rio de Janeiro: Rocco, 1990. 


\section{ANEXO}

A

Figura 1: Conjunto Habitacional Irmã Dulce (faixa 1).

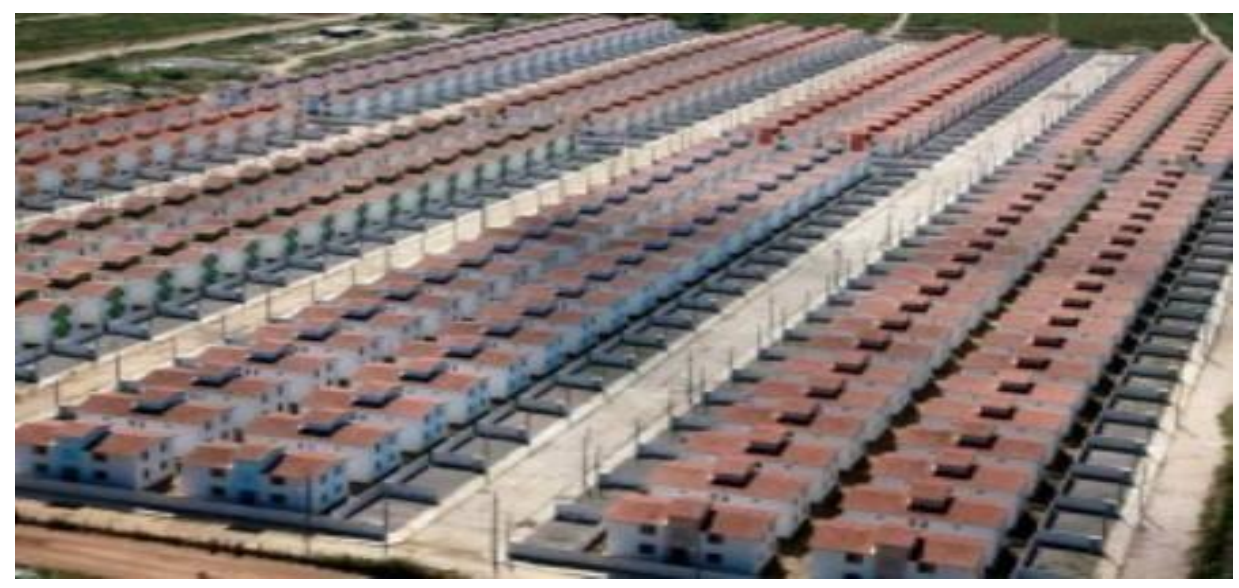

Fonte: Endereço eletrônico da Prefeitura Municipal de João Pessoa $(2012)^{7}$. Figura 2: Residencial Jardim Veneza (faixa 1).

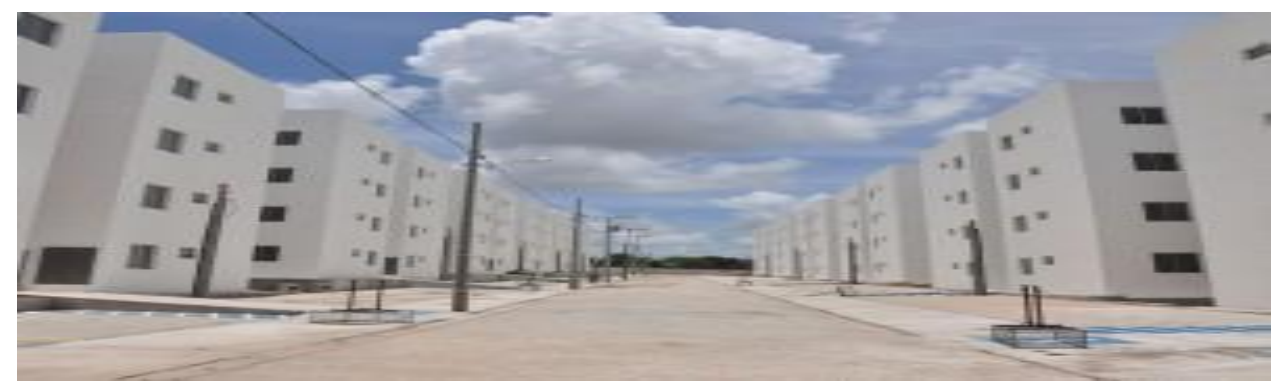

Fonte: Endereço eletrônico da Prefeitura Municipal de João Pessoa

$(2012)^{8}$. Figura 3: Residencial Manacá (faixa 1).

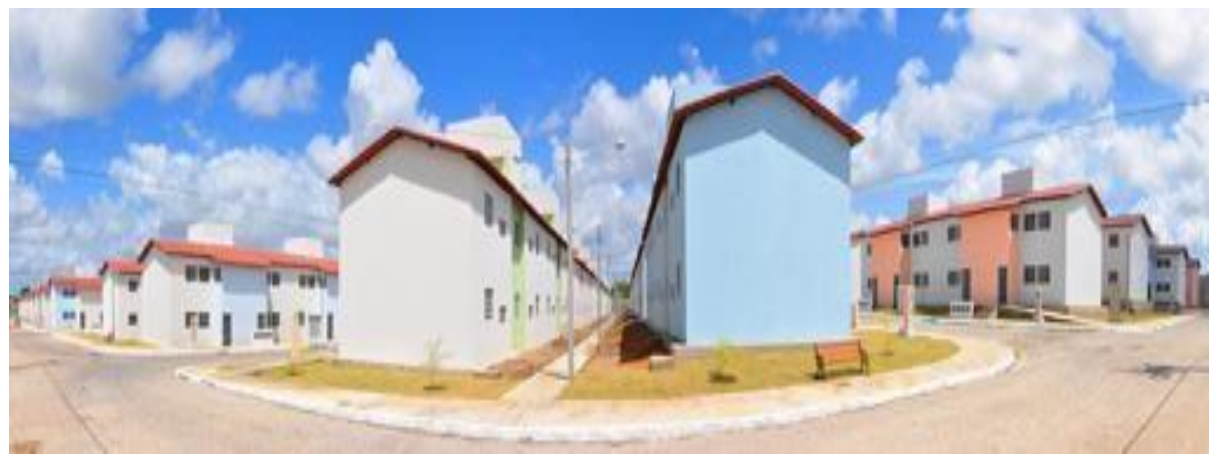

Fonte: Endereço eletrônico da Prefeitura Municipal de João Pessoa $(2012)^{9}$.

\footnotetext{
7 Disponível em: <http://www.joaopessoa.pb.gov.br/prefeito-entrega-residencial-anayde-beiriz-e-beneficia584- familias-carentes/ >. Acesso em: 29 jul. 2013.

${ }^{8}$ Disponível em: 〈http://www.guiamais.com.br/guia-de-bairros/jardim+veneza-joao+pessoa-pb〉. Acesso em: 29 jul. 2013.

${ }^{9}$ Disponível em: <http://op.joaopessoa.pb.gov.br/?p=1439>. Acesso em: 29 jul. 2013.
} 


\section{ANEXO B}

Figura 4: Residencial Eleonora Coutinho (faixa 3).

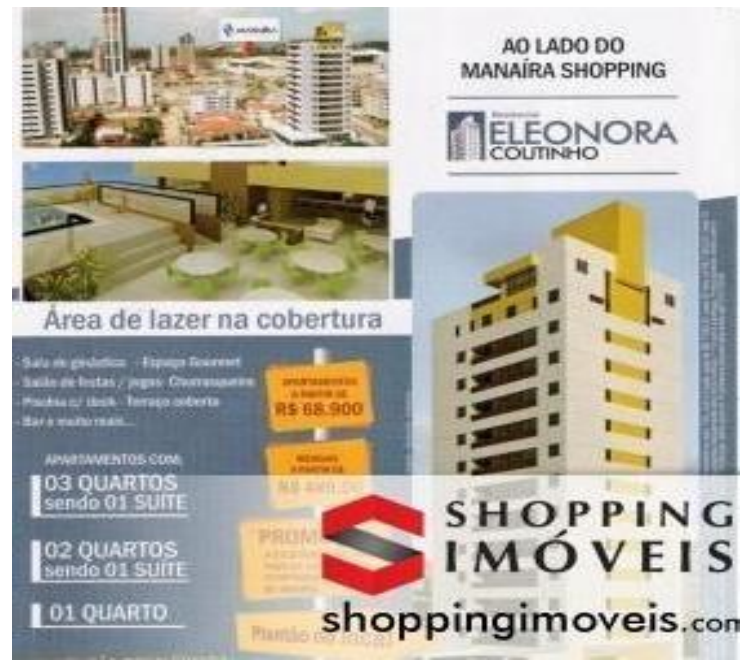

Fonte: Endereço eletrônico da OLX $(2013)^{10}$.

Figura 5: Residencial Spazio di Napoli (faixa 3).

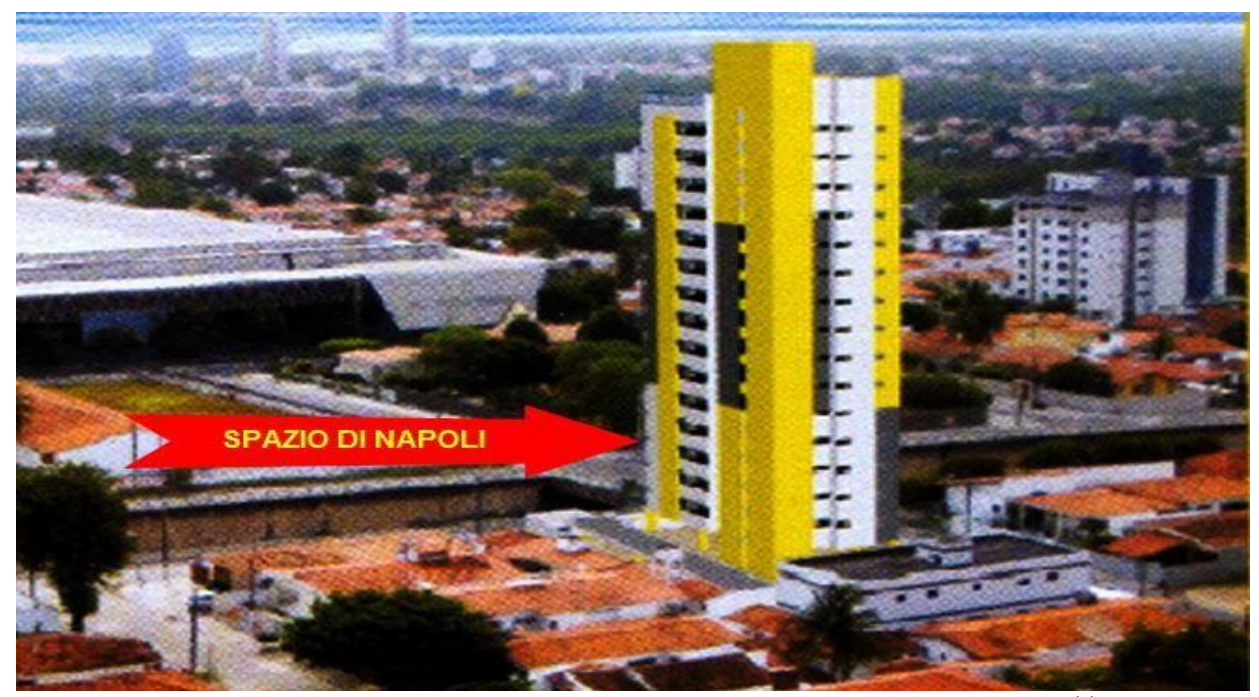

Fonte: Endereço eletrônico do Stand de Vendas $(2013)^{11}$.

\footnotetext{
${ }^{10}$ Disponível em: <http://www.olx.com.br/395-residencial-eleonora-coutinho-3-quarto-s-joao-pessoa-r-18400000-iid-447290760>. Acesso em: 31 ago. 2013.

${ }^{11}$ Disponível em: <http://www.standdevendas.com.br/imoveis/paraiba/joaopessoa/venda/apartamento/tambauzinho/2-quartos/imovel-12287 >. Acesso em: 31 ago. 2013.
} 